\title{
Comunicación y religión: la comunicación a la luz del Tratado de historia de las religiones de Mircea Eliade
}

\section{Communication and religion: communication in the light of Mircea} Eliade's Tratado de historia de las religiones

\author{
Mercedes Milagro Sarapura Sarapura*
}

Escuela Profesional de Ciencias de la Comunicación, Universidad de San Martín de Porres, Perú

\section{Resumen}

Todos los quehaceres humanos tienen sentido en la medida en que están ligados a una realidad trascendente (Eliade, 2001), y a ello no es ajena la comunicación que, además de ser una de las características ontológicas del hombre, resulta la única vía que permite la experiencia religiosa entendida como una interacción con lo sagrado; y así como ocurría con el hombre primitivo, en la actualidad el principal drama del hombre posmoderno se sitúa, precisamente, en la ruptura con su dimensión religiosa.

La contrastación analítica entre religión y comunicación a partir de los estudios de Mircea Eliade deja en claro cómo confluyen de manera admirable la comunicación y la religión, con la misma intensidad de dos olas que se abrazan en el horizonte de la existencia. El hombre es un ser religioso irrevocable en la medida en que tiene sed de comunicación, en cuyo ámbito sabe que encontrará su propia realización.

Palabras clave: comunicación, religión, semiótica, trascendencia, ciencia, otredad. 


\begin{abstract}
All human tasks make sense to the extent that they are linked to a transcendent reality (Eliade, 2001), and communication is not alien to this, which, in addition to being one of ontological characteristics of man, is the only way that allows the religious experience understood as an interaction with the sacred; and just as it happened with primitive man, at present the main drama of postmodern man is situated precisely in the rupture with his religious dimension.
\end{abstract}

The analytical contrast between religion and communication based on Mircea Eliade's studies makes it clear how communication and religion converge in an admirable way, with the same intensity of two waves that embrace on the horizon of existence. Man is an irrevocable religious being insofar as he thirsts for communication, in which he knows that he will find his own fulfillment.

Keywords: communication, religion, semiotics, transcendence, science, otherness.

\title{
Introducción
}

El hombre es un ser religioso porque es «un ser en relación» consigo mismo, con los demás y con la trascendencia, y relacionarse es la única vía por la que es capaz de abrirse al misterio de la revelación divina, fuente de verdadero conocimiento cuando permite que su razón entre a dicho ámbito de lo infinito (Juan Pablo II, 1998). Se evidencia así un estrecho y profundo vínculo entre comunicación y religión. La comunicación como la característica del ser humano que se fundamenta en la confianza, y la religión -que viene del latín religio (re que indica intensidad, ligare que significa ligar e ión que es acción)- entendida como el acto y efecto de ligar fuertemente con la divinidad.

Asimismo, a partir de sus creencias el hombre primitivo elabora gestos y símbolos que representan y a su vez están dirigidos a seres superiores cuya omnipresencia reconoce. Incluso en estas instancias se evidencian los 
elementos del proceso comunicativo: el hombre, que tiene creencias -las que vendrían a ser su marco de referencia-, construye mensajes, estructuras de significación que excitan los significados en su mente y en la de aquellos a quienes están dirigidas tales estructuras, un otro cuyo misterio contempla y lo desafía. En efecto, la interacción comunicativa está muy ligada a la historia espiritual de la humanidad (Eliade, 1974).

Mircea Eliade estudia a fondo la naturaleza y sentido de las hierofanías -manifestaciones de lo sagrado- en las diferentes culturas primitivas, y no demora en señalar que los gestos, que son intrínsecamente comunicativos, tienen un origen religioso:

Lo cierto es que todo lo que el hombre ha manejado, sentido, encontrado o amado pudo convertirse en hierofanía. Sabemos, por ejemplo, que, en conjunto, los gestos, las danzas, los juegos infantiles, los juguetes, etc. tienen un origen religioso: fueron en otro tiempo juegos u objetos cultuales. (Eliade, 1974, p. 35)

Todos los elementos pertenecientes a la realidad humana que menciona Eliade constituyen la cultura y es esta la otra cara de la comunicación humana. Raymond Williams (citado por Entel, 1995) define la cultura como el proceso en el que significados y definiciones son construidos en sociedad y transformados a través de la historia; mientras que una de las definiciones más asiduas de la comunicación es la de asumirla como un proceso (Berlo, 2000) que supone la construcción de estructuras de significación sujetas a un contexto determinado. Por su parte, Mead señala que el acto social es la unidad más primitiva, definida a partir de sus estudios por su discípulo Blumer como «interaccionismo simbólico», que Mead consideraba como la actividad más humana (Fernández y Galguera, 2009); esto es, «hablar el uno con el otro». En esa misma dirección, Talcon Parsons define la cultura como «un discurso simbólico colectivo» (citado por Kuper, 2001, p. 34).

En consecuencia, la condición simbólica de la comunicación humana resulta ineludible, los mensajes humanos conducen a un algo más que no es fácilmente perceptible. Eliade (1974) observa que todos los oficios y técnicas tienen un origen sagrado; por tanto, valores cultuales. Lo cultual, entendido como el acto de dar culto, ya es en sí una consideración implícita 
de la existencia de un ser superior, y es también un acto expresivo, compatible con el concepto que define cultura como un discurso simbólico; por lo que se puede concluir que todo lo que hace el hombre es expresión de algo, es un salir de sí hacia algo o alguien cuyo mensaje es irrevocablemente de carácter simbólico y, más aún, si se dirige a dioses como los de la naturaleza (el sol o los árboles).

Para algunos científicos el pensamiento abstracto se origina hace más de 40 mil años; no obstante, la génesis del lenguaje podría remontarse a tres y medio millones de años antes (Maturana, 1997), momento en el que surgen -además del lenguaje- el arte y la religión. Es entonces cuando el hombre toma conciencia de su existencia y de su entorno, y sale de sí al encuentro de sus semejantes, con los que crea fuertes vínculos de convivencia, trabajo, crianza de la prole, etc.; y sale también al encuentro de unos seres superiores representados por animales, fenómenos naturales y otros elementos de la naturaleza, con los que también intenta relacionarse mediante vías de comunicación que se podrían llamar cultuales y que con el tiempo devendrían en expresiones religiosas, entendidas como una serie de actos que servirán para crear fuertes vínculos con dichos seres sagrados. Por todo ello, la religión podría entenderse también como una experiencia comunicativa trascendente a edad temprana.

En suma, a partir de entonces, el hombre inicia una relación con su entorno, con sus semejantes, y al contemplar la naturaleza intuye la presencia de unos seres superiores con los que intenta comunicarse. Las primeras culturas tenían una relación lejana con la deidad, considerada celeste, buena pero desentendida de las vicisitudes cotidianas del hombre; mas, en la medida en que fenómenos naturales como la lluvia o la sequía afectaban o intervenían en sus quehaceres, comenzó a considerarlos divinidades o manifestaciones de la ira divina, por lo que había que rendirles algún tributo o sacrificio como pago por los errores o malos actos humanos. De ahí que la relación del hombre con la divinidad se inicia como una transacción entre unos seres inferiores y otros superiores, basada en muchos casos en sentimientos de culpa y de reparación.

Muy pronto muchas actividades y elementos de la naturaleza asumirían un carácter sagrado, por lo que se produciría un quiebre existencial entre 
lo sagrado y lo profano, como sostiene Eliade (1974). El autor observa asimismo que la expresión de lo sagrado en la materia sería una prefiguración del misterio de la encarnación y que lo ininteligible no es que lo sagrado se manifieste en la materia, sino que se limite y se haga relativo; sin duda, con el fin de hacerse accesible al hombre y con el único propósito de unirse o ligarse a él, aunque al principio solo a través de la madera o la piedra como una expectación remota de lo que más adelante sería Cristo. Más que una cosa perteneciente a Dios, en ese extraordinario caso sería Él mismo hecho hombre, por lo que desde la perspectiva del cristianismo las hierofanías de los pueblos primitivos no serían del todo aberrantes.

Más aún, la historia revela que en las religiones primitivas la divinidad se integra a la condición humana. Impulsado por un ardoroso deseo de lo concreto, el hombre coloca a las divinidades celestes -otrora indiferentes y distantes de su vida cotidiana- en segunda fila, donde destaca la importancia del 'hijo' del dios del cielo, como ocurre con Osiris, Dionisos o Alein (Eliade, 1974). Por tanto, resulta evidente que todas las religiones confluyen en un impetuoso afán de acercarse a la deidad, de bajarla de los cielos e interactuar con ella; modos que prefiguran y se mantienen expectantes de lo que más adelante sucedería en el pueblo hebreo.

En este aporte se intenta ahondar en la estrecha relación existente entre religión y comunicación, si se advierte que esta facultad se origina hace millones de años en un ambiente de cálida convivencia (Maturana, 1997), entendida como el deseo interior del ser humano de salir de sí, hasta llegar a entablar una misteriosa relación con seres superiores cuyas presencias advierte en los distintos elementos que lo rodean y a los que dota de especiales significaciones que devienen en hierofanías.

De igual manera, esta propuesta intenta resaltar la relación entre comunicación y religión por el hecho de que el hombre no ha nacido para estar solo, como señala Juan Pablo II (1998):

sino en familia; para luego crecer en sociedad con unas tradiciones de las que hereda no solo el lenguaje y la formación cultural, sino también muchas verdades en las que, casi instintivamente, cree. De todos modos, el crecimiento y la 
maduración personal implican que estas mismas verdades puedan ser puestas en duda y discutidas por medio de la peculiar actividad crítica del pensamiento. (p. 19)

En primer lugar, se aborda la relación entre razón y verbo, términos que tienen procedencia común, a partir de la cual se advierte que comunicación y razón no son posibles sin trascendencia; luego se analiza el sentido religioso, presente tanto en el hombre primitivo como en el contemporáneo, y sobre los problemas de este al sustraerse de dicho sentido; para, finalmente, ahondar en la necesidad de la fe como fundamento de una auténtica experiencia comunicativa.

\section{Razón y palabra: al principio era el Verbo}

El evangelio de san Juan comienza con esta aseveración: «en el principio era la Palabra [...] y la Palabra era Dios» (Jn1, 1-2). Se sabe que el hombre es el ser del logos -término que significa razón y palabra- y, ciertamente, la interacción comunicativa revela al ser, mientras que la palabra resulta un vínculo ontológico (Acerca de Razón y Palabra, 2021).

De ahí que es posible inferir que el ser del logos surgió al mismo tiempo que el homo religiosus, por lo que no debería haber ninguna tensión $\mathrm{u}$ oposición entre razón y religión, más aún si se entiende la experiencia religiosa como una experiencia comunicativa que conlleva la búsqueda de la verdad, propósito último de la razón humana, que precisamente se sostiene en el diálogo confiado, como señala Juan Pablo II (1998); especialmente en la amistad, considerada por los antiguos filósofos como contexto idóneo para el buen filosofar, pero equivocadamente dejada de lado por una postura escéptica propia de la investigación especulativa.

En ese mismo sentido, Jaspers define la comunicación existencial como aquella que trasciende la existencia empírica porque es estrictamente interpersonal y se fundamenta en la libertad: «yo solo soy yo mismo cuando el otro es y quiere ser sí mismo y yo con él» (citado por Villarino, 2009, p. 55).

Eliade considera que la experiencia religiosa mueve por entero la vida del ser humano y esto no ha cambiado si se contrasta al hombre primitivo 
con el hombre posmoderno: «hemos tenido ocasión de ver que la 'razón' no estaba ausente de las hierofanías más arcaicas, que la experiencia religiosa no es a priori incompatible con la inteligibilidad. Lo tardío y artificial es la primacía exclusiva de la razón» (1974, p. 158). Por tanto, el drama religioso del hombre moderno se inicia con la primacía de la razón, que además se contrapone a la religión, la cual pasa a ser una experiencia subjetiva y privada, anulando toda forma de comunicación no solo con la trascendencia, sino del hombre con el hombre, y exilia lo sagrado de un escenario que se tornará única y necesariamente profano.

No obstante, la palabra es el fruto más notable de la razón humana, su expresión mejor consumada que deviene en signo; la razón crea signos y estos constituyen el lenguaje, una estructura compleja que concretiza lo abstracto y hace presentes realidades ausentes. Es solo de esa manera como el hombre sale de sí para referirse a la existencia sensible, a su mundo interior y también a una posible existencia superior.

En la antigüedad nadie define tan bien los signos como san Agustín, quien -a su vez- deja demostrado que la teología servirá de base para explicar el problema semiótico (citado por Castañares, 2014). Agustín sostendrá que el lenguaje es «el sistema semiótico por excelencia, mediante el cual los hombres se comunican entre sí y pueden informarse mutuamente» (citado por Castañares, 2014, p. 234). Reconoce asimismo la función comunicativa de los signos, ya que es con ellos que los hombres se comunican dado que no es posible hacerlo de espíritu a espíritu. Para él los signos se clasifican en naturales y en dados: los primeros tienen un significado involuntario, como las huellas o los gestos; mientras que los signos dados tienen detrás una intencionalidad porque surgieron con el fin de significar. Las hierofanías corresponderían al primer tipo de signos, pues su sola e imponente presencia señalaban a Otro.

El modelo triádico que Agustín propone coincide con el modelo triádico de Charles Pierce. El pensamiento vendría a ser la voz interior o del corazón, sostiene Agustín, que se ve pero no se oye: «el lenguaje del corazón es de naturaleza muy distinta, no tiene sonido ni sílabas ni palabras» (citado por Castañares, 2014, p. 243); en cambio, la palabra exterior se convierte en sonido aunque se piense en silencio. Y es así como Agustín precisa una 
semejanza entre la segunda persona de la Santísima Trinidad, el Hijo, con el pensamiento humano: «el Verbo divino se hace carne, aunque no quede reducido a la carne, así la palabra interior se hace sonido, aunque sin ser mero sonido» (citado por Castañares, 2014, p. 244).

De hecho, para san Agustín el hombre conoce la inteligencia y la iluminación divina a través de los sentidos; considera que la sabiduría se ocupa de la contemplación de lo eterno, mientras que la ciencia se dedica al estudio de las cosas temporales. Por lo cual, con el surgimiento del racionalismo, al quedarse únicamente con la ciencia y las realidades temporales, el hombre limita sus posibilidades de acceso a la verdad y olvida que para ello no solo tiene a la razón, sino también la opción de confiar en los demás (Juan Pablo II, 1998), abandono confiado en los otros en función no solo de sus aciertos científicos, sino de sus experiencias culturales; es decir, de sus valores y creencias heredadas.

Asimismo, una de las fuentes del saber humano, además del conocimiento que el individuo puede adquirir por sí mismo y de forma sensible, es el testimonio de los otros (Agustín, citado por Castañares, 2014), lo que prueba la importancia de la interacción comunicativa y de la confianza, pues la sabiduría adquirida a partir de la comunicación con los otros resulta enriquecedora porque procede de vínculos interpersonales íntimos (Juan Pablo II, 1998).

Con todo ello, al despojarse el hombre de una de sus vías de acceso al conocimiento: la fe, se desvincula de la creación, anula toda posibilidad de conexión con alguna deidad y, por último, segrega la interacción con sus congéneres y se fragmenta; no obstante, el hombre posmoderno es aún un hombre religioso cuyo instinto lo conduce a través del arte y de la propia rebeldía. Sin embargo, como señalaba Eliade (2001), ya entonces y ahora, la preocupación central está en torno a las posibilidades espirituales porque permiten el conocimiento del ser humano y de su historia.

\section{El hombre contemporáneo como el primitivo}

El ser humano de todos los tiempos lleva inherente a su natural forma de ser la necesidad de convertir en objeto de significación las cosas y sus 
actos, solo que de manera más sofisticada. Esta vez no serán el aire, la lluvia ni el sol, pero sí la ropa, la comida, los libros, las películas, los templos y edificios como otrora; y, por supuesto, los actos que realiza los fines de semana, los días comunes y festivos, asumidos como ritos habituales a los que, aunque involuntariamente, confiere un carácter sagrado. Baudrillard (1969) analiza la significación de los objetos en la vida contemporánea, encontrando que todas las experiencias y cosas se abstraen o materializan. Un viaje postergado a París se materializa en un polo estampado con la imagen de la Torre Eiffel; y así numerosos deseos y cosas que en la vida cotidiana adquieren cierta condición «sagrada».

En esa misma dirección, Eliade sostiene que para los hombres primitivos las cosas y los actos humanos no tenían en sí valor intrínseco autónomo:

una piedra de las más vulgares: será convertida en 'preciosa', es decir, se la impregnará de una fuerza mágica o religiosa en virtud de su sola forma simbólica o de su origen: 'piedra de rayo', que se supone caída del cielo; perla, porque viene del fondo del océano [...]. (2001, p. 7)

Desde una perspectiva semiótica, san Agustín establece una distinción entre las cosas, las cosas-signos y los signos puros; pero considera que desde una perspectiva teológica si todas las cosas han sido creadas por Dios, resultan signos que nos remiten a Él, vestigios del Creador, desde donde el ser humano puede elevarse y conocer la Trinidad (citado por Castañares, 2014), y esta conclusión es la que se reconoce en las hierofanías de todas las religiones del mundo.

En suma, el producto de la naturaleza, los objetos confeccionados por el hombre solo hallan su identidad si tienen un sentido trascendente (Eliade, 2001). La preocupación cotidiana del ser humano es, precisamente, el sentido de las cosas que hace y de todo lo que le rodea, el sentido que es la verdad misma, sujeta a una realidad. Su principal ocupación es expresar ese sentido y comunicarlo, pues -como señala Blumer- la naturaleza de las cosas depende de los significados que les dan los sujetos (citado por Fernández y Galguera, 2009) y esa asignación de significado es colectiva, aunque no cabe duda de que su origen es necesariamente religioso en todas 
las culturas hasta la actualidad. Igualmente, el sentido que se otorga a objetos y actos dependerá de su repetición; de ahí que los acontecimientos que se repiten periódicamente serán los más importantes porque entrañan en sí un rito (Eliade, 2001).

Ahora bien, incluso más allá de los animales, de los objetos y de los actos humanos, el propio ser humano es un objeto sagrado. Goffman (1970) define la comunicación como un ritual, precisamente porque considera que el valor social positivo es «la cara», y esta sería la persona misma, elemento sagrado que necesariamente requiere todo ritual y, por tal, expuesto frecuentemente a desaires y profanaciones.

El contexto en el que el hombre se encuentra cara a cara con su semejante es su propio espacio doméstico y cotidiano, lugar y momento solemnes cuando se bate a duelo, pero sujeto a una serie de reglas con el fin de garantizar el equilibrio de la interacción (Goffman, 1970). De igual manera ocurría por ejemplo en los pueblos primitivos, en los que los ritos sacrificiales eran propuestas reparadoras para procurar el retorno del equilibrio a sus relaciones con sus dioses.

No obstante, con el Renacimiento, cuando la razón humana se erige por encima de cierta ontología original (Eliade, 2001) y se desentiende de toda idea de una posible divinidad externa; y se vuelve más bien tan solo hacia la consideración de valores humanos, ahí cuando «nada sostiene al hombre por encima de sí mismo» (Gomá, 2009, p. 86) es cuando se deslinda de toda explicación mágica de sus orígenes y se encamina a una cultura post-mítica y nihilista, ya sin creencias. Gomá (2009) considera que el hombre ya sin religión y sin patriotismo no será capaz de sacrificar su yo por un bien comunitario y esta sería la crisis de la comunicación existencial por la que atraviesa ahora la humanidad.

El autor explica que el hombre ha de transitar de un estadio estético en el que se hace consciente de su propia singularidad a un estadio ético en el que se encuentra con el otro, lo acepta y lo asume, pero que necesariamente tiene que darse sobre una estructura ética; es decir, de valores cuyas raíces ineludiblemente se remiten a las creencias sagradas del hombre arcaico. 
No obstante, al romper con el hombre arcaico, rompe con toda idea de trascendencia y se centra en sí mismo como un nuevo absoluto sobre la base de su libertad, quebrándose también la paideia, que Gomá (2009) define como un dualismo vertical que implica una relación participativa entre lo visible de abajo y lo invisible superior, y que se transforma en una dualidad paralela antagónica que implica más bien el mundo interior del ser humano y el mundo exterior exento de todo simbolismo y de todo ideal.

El ensimismamiento del hombre que niega toda realidad absoluta, extrahumana (Eliade, 2001), se entiende como una ruptura cuya consecuencia es semejante a lo que les ocurrió a los humanos en la torre de Babel: se volvieron incapaces de entenderse a sí mismos y a los demás. El hombre no ha renunciado a los ritos porque en mayor o menor medida aún los realiza, pero sí a los mitos que los justifican, en su afán de admitir tan solo lo que la luz de la razón es capaz de explicar. Y peor aún, con ello ha renunciado a la propia realidad porque, como señala Eliade (2001), la realidad entendida también como sentido solo se adquiere por repetición o participación, y esto es únicamente posible cuando se tiene un modelo ejemplar; por lo que, aunque repita ritos, al desentenderse de los mitos que les confieren sentido, cae en la cuenta de que lo que hace carece de sentido, hasta que deja de hacerlo. Por ello, a decir de Gomá, es importante la reivindicación de la ejemplaridad.

La mirada crítica del hombre moderno objeta que el hombre tradicional solo se asume como existente cuando deja de ser él mismo para imitar a otro (Eliade, 2001); pero, más bien, ello se debe entender como una necesidad de descubrirse en el otro y de asumirlo como referente ejemplar, pues todas las actividades humanas tienen un prototipo mítico, como por ejemplo la justicia, que se basa en la ley cuyo modelo son las reglas cósmicas (Eliade, 2001).

El hombre primitivo rechaza la historia, considera significativo solo aquello que se repite periódicamente mediante ritos que anulan el tiempo profano y permiten revivir o experimentar eternamente lo que vivió en el estado original; por ello es que para él todo se repite cíclicamente sin cesar. Por su parte, el hombre moderno asume su condición histórica y aunque el Dios judío también reivindica la historia, con Él progresa la idea de los 
acontecimientos históricos (Eliade, 2001), pues estos adquieren valor religioso al ser determinados por la voluntad de un dios que pasa a ser una personalidad que interviene en la historia y se manifiesta a través de los aconteceres. De ahí que los hebreos resultan los primeros en entender la historia como epifanía, concepción perfeccionada después por el cristianismo.

En contraste, en función del materialismo histórico, el hombre moderno asume su condición de ser histórico que construye una verdad y a la que ya no asume como revelada. Es el ser de la acción comunicativa (Habermas, 1992), inmanente y desprovisto de toda trascendencia, de toda sacralidad $\mathrm{y}$, por ende, desmotivado para cualquier tipo de gesta heroica en función de unos ideales o valores que a sus ojos no son más que relativos. Por otro lado, cabe destacar que el cristianismo asume el valor de los acontecimientos históricos que hereda del judaísmo, pero con más fuerza, dado que para él la incursión de Dios en la historia ya no es una promesa, sino una realidad; conservando también la idea valorativa del rito que se repite periódicamente con el memorial de la Pasión de Cristo en la Eucaristía.

\section{La fe como fundamento del encuentro}

La necesidad de realizar hipóstasis, que puede ser una forma de entender las hierofanías, acusa al hombre de su urgencia de crear un vínculo con lo eterno o con lo que intuye que permanece antes y después que él. Eliade explica que hay un momento en el que el sacrificio de las primicias que todas las culturas arcaicas ejecutaban por costumbre y eran previstas, de pronto adquiere otro cariz con la experiencia de Abraham. Cuando Dios le pide el sacrificio de su unigénito, experiencia de fe que inaugura una nueva teofanía que anula la validez de otras hierofanías, Abraham no entiende por qué le pide ese sacrificio y, sin embargo, se apresta a cumplirlo. Dicho acto de fe inicia una nueva experiencia religiosa: si para las culturas arcaicas los actos de ofrenda no eran más que «la circulación de la energía sagrada en el Cosmos» (Eliade, 2001, p. 69), para Abraham son más que eso y no menos desconcertantes, pues su hijo era un don de Dios.

El acto religioso de Abrahán inaugura una nueva dimensión religiosa: Dios se revela corno personal, como una existencia 'totalmente distinta' que ordena, gratifica, pide, sin ninguna 
justificación racional (es decir, general y previsible) y para quien todo es posible. Esa nueva dimensión religiosa hace posible la 'fe' en el sentido judeocristiano. (Eliade, 2001, p. 69)

Esta nueva dimensión religiosa inaugura también, y sin lugar a dudas, la experiencia más profunda de la comunicación humana, pues inicia una relación personal con la divinidad, que ya no es más parte de un ciclo sagrado previsible, sino un ser personal dotado de libertad, capaz de hacer y deshacer normas, capaz de ser libre y de reconocer la libertad del hombre, y que se consuma cuando el Dios judío entra en la historia y esta se convierte en una teofanía.

El pensamiento cristiano tendía así a superar definitivamente los viejos temas de la eterna repetición, del mismo modo que se había esforzado por superar todas las demás perspectivas arcaicas mediante el descubrimiento de la importancia de la experiencia religiosa de la 'fe' y la del valor de la personalidad humana. (Eliade, 2001, p. 87)

Desde la fe, el hombre reconoce la verdad de lo revelado, que adquiere posición central en la comunicación interpersonal y que insta a la razón a acogerla en su sentido más profundo (Juan Pablo II, 1998). La verdad inserta en dicho horizonte supone una relación interactiva enriquecedora, en la que tienen lugar sucesivos actos de empatía, entendida como aprehensión de un acto sentimental que hace posible penetrar en el reino del espíritu, de los valores (Stein, 2004).

$\mathrm{Al}$ cabo de un largo recorrido a través del tiempo en su relación con los dioses, el hombre ha entendido aquello que Stein (2004) considera importante: que el acceso a dicha relación se dio a partir de las experiencias de la expresión. Por siglos, el ser humano aprendió a leer la furia divina en los temibles fenómenos naturales, así como su correspondencia, etc.; y aprendió también a responder de diferentes maneras, respuestas que serían evidencia de lo que la autora entiende como la incursión del espíritu en el mundo físico, ya que todo lo moldeado por la mano del hombre, que sería el mundo cultural, es manifestación de su espíritu (Stein, 2004). 
La autora también destaca que un sujeto espiritual aprehende a otro y que esto contribuye mucho a su propio autoconocimiento si se trata de un otro semejante, al descubrir lo que hay del otro dormido en sí mismo, así como ayuda a su autovaloración que, frente al otro, lo lleva a ser consciente de la propia carencia o desvalor. Y este es el camino que, no sin esfuerzo, el cristiano inicia con mayor ahínco a partir de la incursión histórica de Dios, revelación que solo le es posible comprender a él y desde entonces a cualquier hombre del mundo a partir de la fe. De ese modo, tras muchos intentos, al fin, con la experiencia de Abraham, el hombre puede comunicarse con Dios cara a cara.

\section{Conclusiones}

El fenotipo ontogénico, sostiene Maturana (1997), que permite la conservación del linaje humano desde hace millones de años hasta la actualidad, es justamente un estilo de vida homínido que posibilita el lenguaje; y sería el amor el que da origen a dicho estilo de vida porque procura el espacio de acciones de ese modo de vivir; emoción, por ello mismo, determinante en la historia de la evolución. Por tanto, es su modo de ser comunicante el que busca salir de sí para expresar y crear vínculos fuertes con sus semejantes, con los demás seres vivos y con la trascendencia.

En efecto, la comunicación llegará a su plenitud solo si se fundamenta en la fe, entendida como la confianza puesta en las creencias de los demás y en las propias, en un intento por retornar a los valores de los antepasados (Gomá, 2009), que permitirán aprovechar -con la facilidad del hombre arcaico- la iluminación divina que refiere san Agustín (citado por Castañares, 2014) como una de las formas esenciales del conocimiento humano. Esa voz interior cuyo origen no proviene de ninguna lengua, pero que busca hipostasiarse en los elementos del entorno, como ocurría con las hierofanías (Eliade, 1974) en tiempos arcaicos, cuando la relación con la deidad se iniciaba distante y transaccional hasta arribar a la era del cristianismo, cuando la experiencia religiosa llega a su plenitud como encuentro personal sobre la base de una relación de amor. 


\section{Referencias}

Baudrillard, J. (1969). El sistema de los objetos. Siglo XXI.

Berlo, D. (2000). El proceso de la comunicación. Introducción a la teoría y a la práctica. El Ateneo.

Castañares, W. (2014). Historia del pensamiento semiótico. 1. Antigüedad grecolatina. Trotta.

Eliade, M. (1974). Tratado de historia de las religiones. Ediciones Cristiandad.

Eliade, M. (2001). El mito del eterno retorno. Emecé.

Entel, A. (1995). Teorías de la comunicación. Editorial Docencia.

Fernández, C. y Galguera, L. (2009). Teorías de la comunicación. McGraw-Hill.

Goffman, E. (1970). Ritual de la interacción. Editorial Tiempo Contemporáneo.

Gomá, J. (2009). Ejemplaridad pública. Taurus.

Habermas, J. (1992). Teoría de la acción comunicativa I. Racionalidad de la acción y racionalidad social. Taurus.

Juan Pablo II (1998). Carta encíclica Fides et ratio. Salesiana.

Kuper, A. (2001). Cultura. La versión de los antropólogos. Paidós Ibérica.

Maturana, H. (1997). Lenguaje y realidad: el origen de lo humano. Revista Colombiana de Psicología, 5-6.

Acerca de Razón y Palabra. (2021, 18 de noviembre). Razón y Palabra. http://razonypalabra.org.mx/sobrerp.html Stein, E. (2004). Sobre el problema de la empatía. Trotta.

Villarino, H. (2009), Karl Jaspers: La comunicación como fundamento de la condición humana. Editorial Mediterráneo. 